\title{
Corticotroph adenoma and pituitary fungal infection: a rare association
}

\author{
Diana Catarino, Cristina Ribeiro, Leonor Gomes and Isabel Paiva \\ Endocrinology, Diabetes and Metabolism Department, Centro Hospitalar e Universitário de Coimbra EPE, \\ Coimbra, Portugal
}

Correspondence should be addressed to D Catarino

Email

diana_catarino@hotmail.com

\section{Summary}

Pituitary infections, particularly with fungus, are rare disorders that usually occur in immunocompromised patients. Cushing's syndrome predisposes patients to infectious diseases due to their immunosuppression status. We report the case of a 55-year-old woman, working as a poultry farmer, who developed intense headache, palpebral ptosis, anisocoria, prostration and psychomotor agitation 9 months after initial diabetes mellitus diagnosis. Cranioencephalic CT scan showed a pituitary lesion with bleeding, suggesting pituitary apoplexy. Patient underwent transsphenoidal surgery and the neuropathologic study indicated a corticotroph adenoma with apoplexy and fungal infection. Patient had no preoperative Cushing's syndrome diagnosis. She was evaluated by a multidisciplinary team who decided not to administer anti-fungal treatment. The reported case shows a rare association between a corticotroph adenoma and a pituitary fungal infection. The possible contributing factors were hypercortisolism, uncontrolled diabetes and professional activity. Transsphenoidal surgery is advocated in these infections; however, anti-fungal therapy is still controversial.

\section{Learning points:}

- Pituitary infections are rare disorders caused by bacterial, viral, fungal and parasitic infections.

- Pituitary fungal infections usually occur in immunocompromised patients.

- Cushing's syndrome, as immunosuppression factor, predisposes patients to infectious diseases, including fungal infections.

- Diagnosis of pituitary fungal infection is often achieved during histopathological investigation.

- Treatment with systemic anti-fungal drugs is controversial.

- Endocrine evaluation is recommended at the time of initial presentation of pituitary manifestations.

\section{Background}

Pituitary infections are rare disorders that represent less than $1 \%$ of all pituitary lesions and may be caused by bacterial, viral, fungal and parasitic infections $(1,2)$. Infections may develop in a normal pituitary gland or in pre-existing pituitary lesions (such as adenoma, Rathke's cleft cyst, craniopharyngioma) (2) and can occur by either hematogenous spread or contiguous extension from adjacent anatomical sites (meninges, sphenoid sinus, cavernous sinus and skull). Central nervous infections, paranasal sinusitis and immunocompromised status (due to, for example, diabetes mellitus, Cushing's syndrome, tuberculosis, organ transplantation, human immunodeficiency virus infection, malignancy and chemotherapy) are risk factors for these conditions. Fungal infections of the pituitary region are extremely rare and usually occur in immunocompromised patients (3).

Cushing's syndrome has long been recognized to predispose patients to infectious diseases, as a consequence of the immunosuppression induced by glucocorticoids (4), 
and such opportunistic infections result in high mortality for patients (5).

\section{Case presentation}

We describe the case of a 55-year-old Caucasian woman, working as poultry farmer, who had been diagnosed with diabetes mellitus for 1 year (since January 2017). At the time of diagnosis, the $\mathrm{A} 1 \mathrm{C}$ was $10.8 \%$ and she was prescribed metformin ( $850 \mathrm{mg}$, twice daily) and gliclazide (60 mg, once daily). She was also diagnosed with arterial hypertension, being medicated with spironolactone (25 $\mathrm{mg}$, daily). The patient had no other known diseases or relevant family antecedents.

Nine months after the diabetes diagnosis (in September 2017), she was hospitalized at a surgery department due to an infected diabetic foot ulcer by staphylococcus aureus, methicillin sensitive. The patient was under the same chronic medication and weighed 67 $\mathrm{kg}$. A1C was $8.1 \%$ and arterial pressure ranged between 125-177 mmHg (systolic) and 53-95 mmHg (diastolic).

During the hospitalization, she developed an acute and severe headache, bilateral palpebral ptosis and anisocoria (without visual impairment) and alternating prostration periods with psychomotor agitation.

A cranioencephalic CT was performed and showed a pituitary expansive lesion, with bone destruction and evidence of bleeding. The first analytical study performed (on September 25th, 2017) revealed a high level of ACTH (1320 pg/mL, reference range (RR): 4.7-48.8), associated with hypothyroidism (FT4: $0.8 \mathrm{ng} / \mathrm{dL}, \mathrm{RR}$ : 0.9-1.8; TSH: $0.07 \mu \mathrm{UI} / \mathrm{mL}$, RR: $0.35-5.5)$ and a low level of prolactin (1.0 ng/mL, RR: 1.8-20.3). However, as this initial assessment was conducted in an external institution, there is no further detailed information about the clinical examination and other analytical parameters.

Patient was transferred to neurosurgery department with suspected pituitary apoplexy and, by then, she was medicated with hydrocortisone (50 $\mathrm{mg}$, twice daily) and L-thyroxin $(50 \mu \mathrm{g} /$ day $)$.

\section{Investigation}

At the neurosurgery department, additional investigation was conducted. Analytical study under medication (on September 28th, 2017) revealed serum cortisol: $22 \mu \mathrm{g} / \mathrm{dL}$ (RR: 5-25), normal high ACTH: 41 pg/mL (RR: 9-52), FT4: $0.9 \mathrm{ng} / \mathrm{dL}$ (RR: 0.8-1.9), TSH: $0.068 \mu \mathrm{UI} / \mathrm{mL}$ (RR: 0.4-4.0), GH: $1.2 \mu \mathrm{g} / \mathrm{L}$ (RR: <1.0), IGF-1: $168 \mathrm{ng} / \mathrm{mL}$ (RR: 81-225), prolactin: $1.1 \mathrm{ng} / \mathrm{mL}$ (RR: <20.0), FSH: $4.2 \mathrm{mUI} / \mathrm{mL}$
(RR: >34), LH: $0.2 \mathrm{mUI} / \mathrm{mL}$ (RR: >25), estradiol: $14 \mathrm{pg} / \mathrm{mL}$ (RR: <20), plasma osmolality: $286 \mathrm{mosmol} / \mathrm{kg}$ (RR: 260302), urine osmolality: 836 mosmol/kg (RR: 300-900) and plasma sodium: $137 \mathrm{mmol} / \mathrm{L}$ (RR: 136-146). Diabetes insipidus was excluded.

MRI revealed a pituitary expansive lesion measuring $27 \times 28 \times 33 \mathrm{~mm}$, with an important infrasellar component, filling of the sphenoid sinus, cavernous sinus compression and invasion to the left, as well as deviation of internal carotid arteries, right deviation of pituitary stalk (without optic chiasm compression) and heterogeneous signal due to the presence of blood content. All these alterations suggested an apoplexy of pituitary macroadenoma (Fig. 1).

\section{Treatment}

Patient underwent transsphenoidal surgery (in October 2017) for subtotal excision of the pituitary lesion, which improved the palpebral ptosis. During the hospitalization, she developed a thoracic herpes zoster infection and was medicated with acyclovir for 10 days ( $1 \mathrm{~g} /$ day).

The patient was discharged under hydrocortisone (10 $\mathrm{mg}$ at wake time and $5 \mathrm{mg}$ in the afternoon), metformin/sitagliptin (1000 mg/50 mg, twice daily) and insulin glargine (5 units at night). There was progressive reduction in the insulin dose, which was stopped after the improvement of glycaemic control.

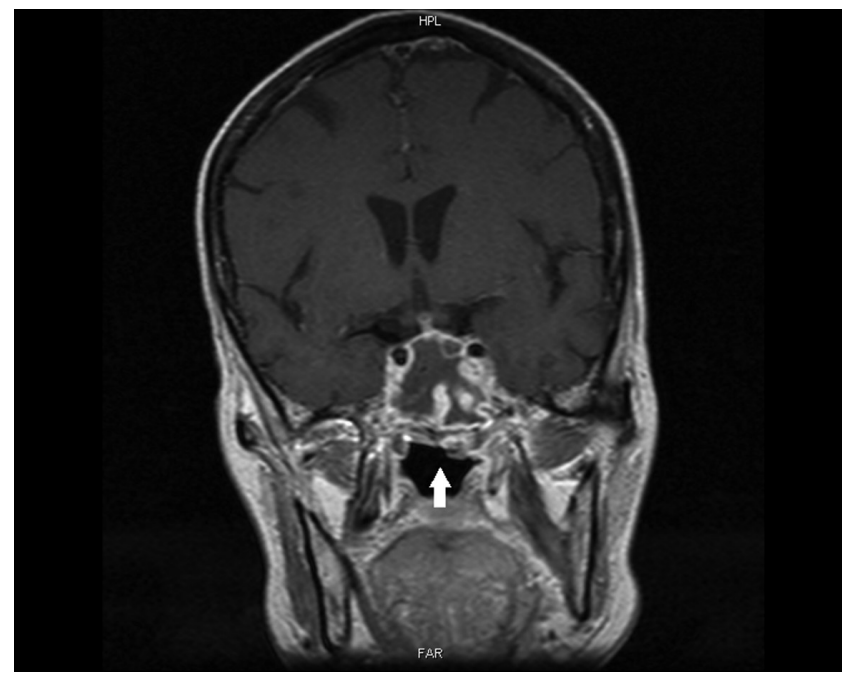

Figure 1

Unenhanced T1 MRI coronal section showing a pituitary expansive lesion (arrow) with heterogeneous signal suggestive of pituitary macroadenoma apoplexy. 


\section{Outcome and follow-up}

Four months after surgery (in February 2018), the patient was readmitted at the Endocrinology Department for re-evaluation and further investigation. She had no signs of Cushing's syndrome, had a slight left palpebral ptosis and weighed only $48 \mathrm{~kg}$.

Analytical study performed after $24 \mathrm{~h}$ of hydrocortisone and L-thyroxin withdrawal revealed hypopituitarism with morning serum cortisol: $1.1 \mu \mathrm{g} / \mathrm{dL}$ (RR: 5-25), АCTH: $6.9 \mathrm{pg} / \mathrm{mL}$ (RR: 9-52) and FT4: $0.7 \mathrm{ng} / \mathrm{dL}$ (RR: 0.8-1.9) (Table 1). There was an improvement on A1C (5.8\%), and the diabetes autoimmunity study was negative.

MRI showed a total excision of suprasellar and anterior sphenoidal component, median position of the pituitary stalk and normal morphology of cavernous sinus (Fig. 2).

The neuropathologic study revealed a corticotroph adenoma measuring approximately $20 \mathrm{~mm}$, with bone destruction and invasion of the sphenoid sinus, recent haemorrhagic content, and bone trabeculae surrounded by osteoblasts, suggesting bone remodelling and fungal infection. There were cell debris surrounding fungal hyphae (Figs 3, 4, 5 and 6).

After the neuropathologic results were reviewed, an extended evaluation was conducted to exclude distant/ systemic fungal infections. Ear and nose examination were normal. Thoracic and abdominal CT scan showed no lesions, and blood cultures and HIV serologies were negative.

The reported case was discussed with infectious diseases physicians and it was decided not to administer systemic anti-fungal treatment given the absence of disseminated infection. After clinical stabilization, the patient was discharged from the endocrinology

Table 1 Biochemical evaluation (before and after surgery).

\begin{tabular}{|c|c|c|c|}
\hline \multirow[b]{2}{*}{ Parameter } & \multicolumn{2}{|c|}{ Result } & \multirow[b]{2}{*}{$\begin{array}{c}\text { Reference } \\
\text { range }\end{array}$} \\
\hline & $\begin{array}{l}\text { Before } \\
\text { surgery }\end{array}$ & $\begin{array}{c}\text { After surgery } \\
\text { (4 months) }\end{array}$ & \\
\hline Cortisol (0800 h) & 22 & 1.1 & $5-25 \mu \mathrm{g} / \mathrm{dL}$ \\
\hline ACTH (0800 h) & 41 & 6.9 & $9-52 \mathrm{pg} / \mathrm{mL}$ \\
\hline $\mathrm{TSH}$ & 0.068 & 1.1 & $0.4-4.0 \mu \mathrm{Ul} / \mathrm{mL}$ \\
\hline FT4 & 0.9 & 0.7 & $0.8-1.9 \mathrm{ng} / \mathrm{dL}$ \\
\hline Prolactin & 1.1 & 4.4 & $<20$ ng/mL \\
\hline $\mathrm{LH}$ & 0.2 & 3.4 & $>25 \mathrm{mlU} / \mathrm{mL}$ \\
\hline FSH & 4.2 & 7.0 & >34 mIU/mL \\
\hline Estradiol & 14 & $<10$ & $<14$ pg/mL \\
\hline $\mathrm{GH}$ & 1.2 & 0.1 & $<1 \mu \mathrm{g} / \mathrm{L}$ \\
\hline IGF-1 & 168 & 47 & $81-225 \mathrm{ng} / \mathrm{mL}$ \\
\hline
\end{tabular}

ACTH, adrenocorticotropic hormone; FSH, follicle-stimulating hormone; FT4, free thyroxine; GH, growth hormone; IGF-1 insulin-like growth factor 1; $\mathrm{LH}$, luteinizing hormone; $\mathrm{TSH}$, thyroid-stimulating hormone.

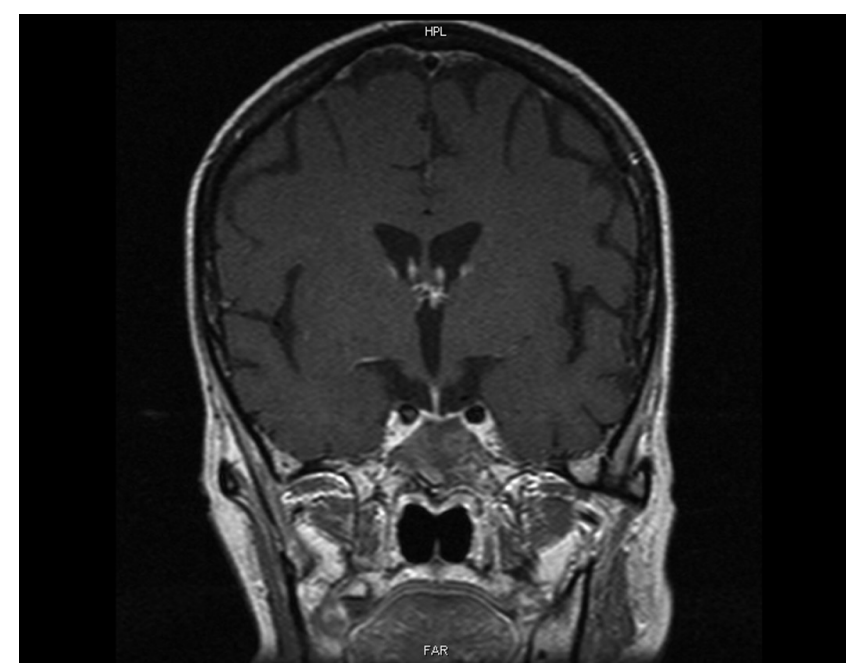

Figure 2

Unenhanced T1 MRI coronal section, 3 months after surgery.

department with glucocorticoid and thyroid replacement therapy (hydrocortisone $10 \mathrm{mg}$ at wake time and $5 \mathrm{mg}$ in the afternoon; L-thyroxin: $50 \mu \mathrm{g} /$ day) and sitagliptin (50 mg, twice daily).

During the follow-up, patient had consultations at infectiology and neurosurgery departments, as well as regular endocrinology visits.

Currently, the same discharge treatment is being maintained. The last analytical study showed FT4: $1.1 \mathrm{ng} / \mathrm{dL}$ (RR: 0.8-1.9), TSH: $0.66 \mu \mathrm{UI} / \mathrm{mL}$ (RR: 0.4-4.0), serum cortisol: $1.1 \mu \mathrm{g} / \mathrm{dL}$ (RR: 5-25), ACTH: $14 \mathrm{pg} / \mathrm{mL}$ (9-52) and A1C $6.2 \%$. There was significant clinical improvement.

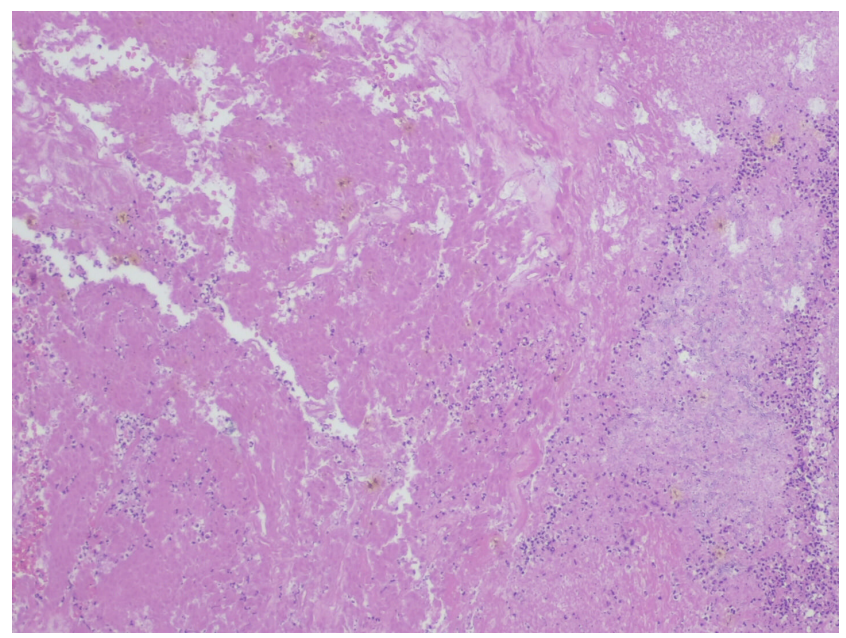

Figure 3

Pituitary adenoma with necrosis to the left and nodular areas with necrosis and septate hyphae to the right. Hematoxylin and eosin stain. $\times 100$. 


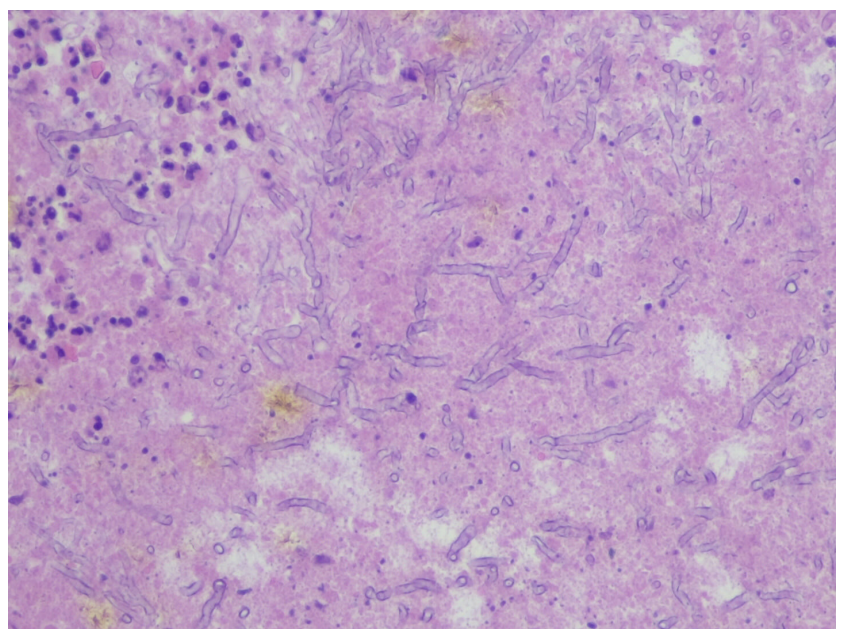

Figure 4

Photomicrograph of the intra-pituitary mass showing fungal organisms with septate hyphae and typical dichotomous branching. Hematoxylin and eosin $\times 400$

\section{Discussion}

Fungal infections of the pituitary region are extremely rare and usually occur in immunocompromised patients. Aspergillus, Nocardia and Candida albicans are the most frequent pathogens in these infections $(2,3)$.

Infection dissemination to the pituitary region can occur through hematogenous spread, direct extension from adjacent structures or iatrogenic (previous surgical intervention in sellar or parasellar region) (2).

An allergic fungal sinusitis designated chronic aspergillosis may, in extremely rare cases, spread from paranasal sinuses to the sphenoidal sinus and then to

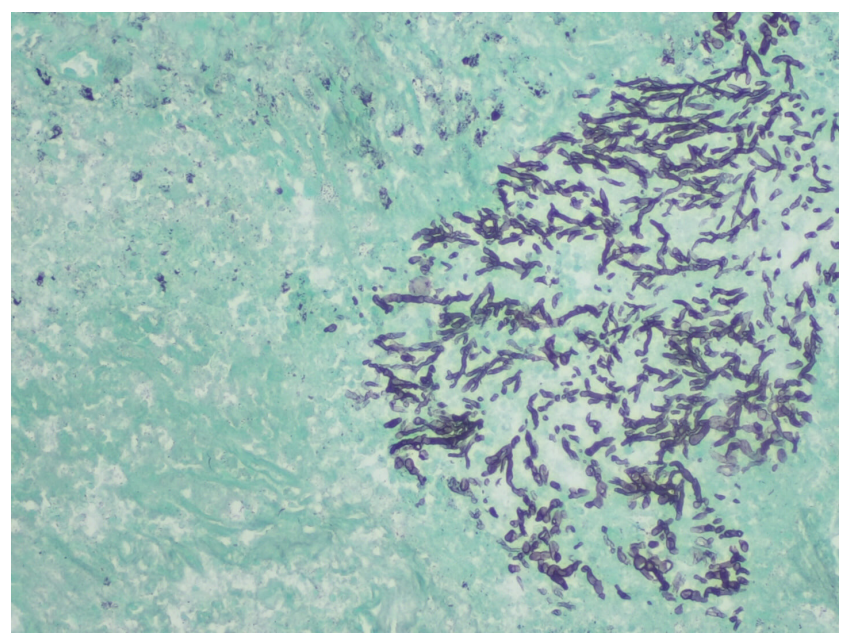

Figure 5

Groccot's methenamine stain method used as a screening for fungal organisms. The cell walls of these organisms are outlined in black $\times 200$.

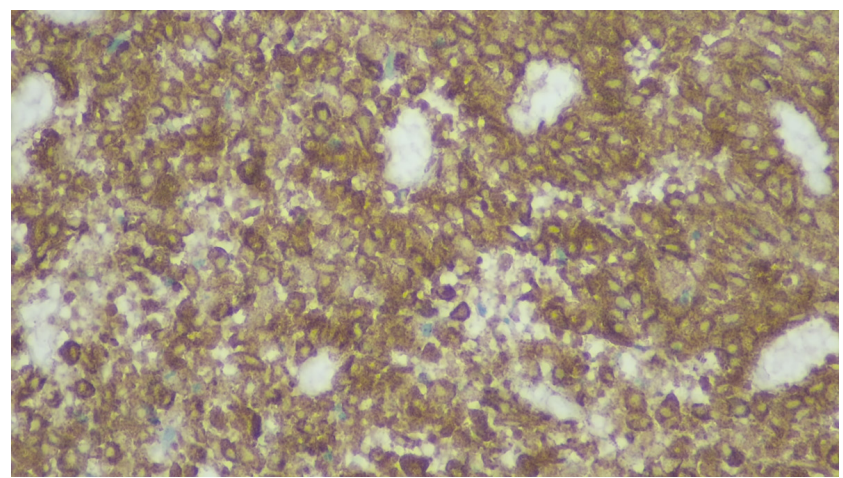

\section{Figure 6}

Pituitary adenoma with a positive staining for adrenocorticotropic hormone $(\mathrm{ACTH})$ on immunohistochemistry $\times 400$.

sellar region, due to the chronic inflammatory infiltrate which may erode the sellar floor. This invasive form is usually seen in immunocompromised patients; however, there are few reports in patients without a documented immunodeficiency $(6,7)$.

Fungal infections of the pituitary region can become apparent through a pseudo-tumour lesion in neuroimaging and the diagnosis is often reached intraoperatively or through histopathological investigation (7). Groccot's methenamine stain demonstrates septate fungal hyphae, and cultivation or PCR identification of fungal DNA allow the correct determination of the fungal microorganism (2).

The treatment consists in transsphenoidal surgery, followed by anti-fungal therapy such as amphotericin B, itraconazole, voriconazole or caspofungin (3).

The controversy is if patients with pituitary fungal infections should be treated with anti-fungal drug when the diagnosis is achieved. Some reports consider postoperative systemic anti-fungal therapy superfluous in cases of total macroscopic lesion excision without subdural involvement. However, other authors suggest a combination of surgery and postoperative systemic antifungal therapy (8).

In this particular case, the correct diagnosis of a corticotroph adenoma (Cushing disease) with pituitary fungal infection was only reached through the neuropathologic study. In fact, the patient had no Cushing's syndrome diagnosis preoperatively and the first diagnosis suspicion was the apoplexy of a previously unknown macroadenoma.

Hypercortisolism associated with poor control of diabetes mellitus led the patient to an immunocompromised status, which is supported by the herpes zoster infection during hospitalization at the neurosurgery department 
and that probably contributed to this rare fungal infection. In fact, it had been already recognised that opportunistic infections by bacterial, viral or fungal pathogens are part of the clinical picture of Cushing's syndrome, carrying high morbidity and mortality (5).

Furthermore, the patient's professional activity can also be considered a possible risk factor to the pituitary fungal infection. Due to the temperature and humidity conditions, poultry farms are favourable places for fungal spread; in fact, studies regarding fungal contamination in poultry farms identified more than 20 fungal species (9).

The authors believe that a possible chronic fungal infection of the paranasal sinuses, derived from the patient's professional activity, contributed to the infection spread.

Fungal detection was achieved through histopathologic findings (Groccot's methenamine stain method) but, unfortunately, culture of the pituitary material was not performed, which made impossible to identify the specific fungal type.

As far as systemic anti-fungal treatment is concerned, a multidisciplinary team decided it should not be performed. In one hand, our patient had no systemic disease and, on the other hand, the pituitary apoplexy associated with surgery allowed for fungal infection suppression, hypercortisolism correction and glycaemic optimization with improvement of the patient's immune status.

Regarding the Cushing's syndrome, both the imaging resolution of the lesion and the persistence of adrenal insufficiency after surgery and the need of glucocorticoid replacement therapy suggest a good prognosis for the patient.

\section{Declaration of interest}

The authors declare that there is no conflict of interest that could be perceived as prejudicing the impartiality of this case report.

\section{Funding}

This research did not receive any specific grant from any funding agency in the public, commercial or not-for-profit sector.

\section{Patient consent}

Written informed consent has been obtained from the patient for publication of the submitted article and accompanying images.

\section{Author contribution statement}

D C has produced the report and performed the literature review. C R and $L G$ assisted in the production of the report and the literature review. I

$P$ oversaw the creation of the report and was involved in the care of the patient. All the authors approved the final version to be published.

\section{References}

1 Pekic S \& Popovic V. Alternative causes of hypopituitarism: traumatic brain injury, cranial irradiation, and infections. In Handbook of Clinical Neurology, Ch. 8, pp 271-290. Eds E Fliers, M Korbonits \& JA Romijn. Edinburg, London: Elsevier, 2014. (https://doi.org/10.1016/ B978-0-444-59602-4.00018-6)

2 Pekic S, Miljic D \& Popovic V. Infections of the hypothalamicpituitary region. 2018 Oct 7. In Endotext [Internet]. Eds KR Feingold, B Anawalt, A Boyce, et al. South Dartmouth (MA): MDText.com, 2000. (available at: https://www.ncbi.nlm.nih.gov/books/NBK53 2083/)

3 Pekic S \& Popovic V. DIAGNOSIS OF ENDOCRINE DISEASE: Expanding the cause of hypopituitarism. European Journal of Endocrinology 2017 176 R269-R282. (https://doi.org/10.1530/EJE-161065)

4 Graham BS \& Tucker WS. Opportunistic infections in endogenous Cushing's syndrome. Annals of Internal Medicine 1984101 334-338. (https://doi.org/10.7326/0003-4819-101-3-334)

5 Bakker RC, Gallas PRJ, Romijn JA \& Wiersinga WM. Cushing's syndrome complicated by multiple opportunistic infections. Journal of Endocrinological Investigation 199821 329-333. (https://doi. org/10.1007/BF03350337)

6 Pekic S, Arsenijevic VA, Gazibara MS, Milojevic T, Pendjer I, Stojanovic M \& Popovic V. What lurks in the sellar? Lancet 2010375 432. (https://doi.org/10.1016/S0140-6736(09)61835-3)

7 Pinzer T, Reiß M, Bourquain H, Krishnan KG \& Schackert G. Primary aspergillosis of the sphenoid sinus with pituitary invasion - a rare differential diagnosis of sellar lesions. Acta Neurochirurgica 2006148 1085-1090; discussion 1090. (https://doi.org/10.1007/s00701-0060811-8)

8 Hong W, Liu Y, Chen M, Lin K, Liao Z \& Huang S. Secondary headache due to aspergillus sellar abscess simulating a pituitary neoplasm: case report and review of literature. Springerplus 20154 550. (https://doi.org/10.1186/s40064-015-1343-6)

9 Viegas C, Viegas S, Veríssimo C, Rosado L \& Santos CS. Possíveis implicações da contaminação fúngica num aviário. Saúde e Tecnologia 20116 17-23

Received in final form 28 February 2020

Accepted 4 March 2020 